\title{
Unilateral pulmonary vein atresia with contralateral upper pulmonary vein atresia in an adult patient
}

\begin{abstract}
Pulmonary vein atresia (PVA) is a very rare anomaly divided into common, individual and unilateral PVA. We report a case of a 54year-old woman who presented with a history of recurrent dyspnea and pulmonary infections. The diagnosis of PVA was suspected in echocardiography and confirmed with $\mathrm{CT}$ angiography which demonstrated absent pulmonary veins except for the left inferior pulmonary vein. Pulmonary arteriography confirmed these findings. In our knowledge, the case of unilateral PVA with contralateral upper pulmonary vein atresia in an adult patient has never been reported in literature.
\end{abstract}

Volume 7 Issue 5 - 2016 Bentaoune T,Arous S, H El Baghdadi, Assaidi
A, Drighil A, Habbal R

Department of Cardiology, IbnRochd University Hospital, Morocco

Correspondence: T Bentaoune, Department of Cardiology, IbnRochd University Hospital, 15, Rue Ibn Khatima, Quartier des hopitaux, Casablanca, Morocco, Tel 2126657449I8, Email bentaounetarik@gmail.com

\section{Introduction}

Pulmonary vein atresia (PVA) is a very rare congenital anomaly associated with high morbidity and mortality. ${ }^{1}$ Depending on the timing in pulmonary veins development defect at the embryonic stage, it can be classified into common, individual and unilateral PVA. ${ }^{2}$ In addition to the type of atresia, the severity of clinical manifestations depends on the amount of collateral blood flow and the presence of an associated congenital heart defect. ${ }^{3}$ Unilateral PVA has been reported in children and adult patients. ${ }^{3,4} \mathrm{~A}$ particular condition of unilateral pulmonary vein atresia with atresia of the contralateral upper pulmonary vein in a child who died at the age of 5 was published. In the present report, we describe the case of a unilateral PVA with contralateral upper pulmonary vein atresia in an adult patient.

\section{Case report}

A 54year-old woman who gave birth to two children, was followed in an outside hospital for a history of chronic dyspnea and asthenia. She presented to the emergency department several times for respiratory failure secondary to recurrent pulmonary infections since her childhood before she was referred to our department for complementary investigations. She presented with cyanotic lips, a pulse oximetry with $90 \%$ saturation, and audible wheezing without cardiac murmur at auscultation. Chest radiography showed bilateral diffuse interstitial lung syndrome. Pulmonary function tests revealed both restrictive and obstructive respiratory patterns. Thoracic computerized tomography (CT) demonstrated ground-glass opacities of the superior and inferior lobes of the right lung and the inferior lobe of the left lung with a small left hemithorax and left mediastinal shift. Results of lung biopsy support non-specific chronic inflammation. No abnormalities were found in laboratory tests including complete blood count, anti-DNA and antinuclear antibodies, anti-SSA, anti-SSB and Waaler-rose test. An electrocardiogram (ECG) and a transthoracic echocardiography (TTE) were performed to assess the impact of lung disease on cardiac structures and functions. Right bundle branch block was found on ECG. In TTE, pulmonary veins (PVs) were not seen except for the right inferior pulmonary vein (PV), right cardiac chambers were dilated without any valvular disease, cardiac defect or impaired ventricular function. To better delineate the anatomy, we choose to perform a cardiac CT with three-dimensional (3D) reconstruction in addition to cardiac catheterization. Cardiac CT highlights the absence of PVs except for the inferior right PV which was dilated and drained into the left atrium (Figure 1), left veinous return was provided by an important collateral blood flow and drained into the left atrium. The right pulmonary artery was dilated (Figure 2). Pulmonary hypertension, possible coexistent congenital heart disease and anatomy of anomalous venous return required cardiac catheterization including pulmonary angiography. Hemodynamic study showed a moderate pulmonary hypertension predominating on the left side. Blood gas analyses did not provide any signs of cardiac shunt. Venous angiography confirmed the cardiac CT findings.

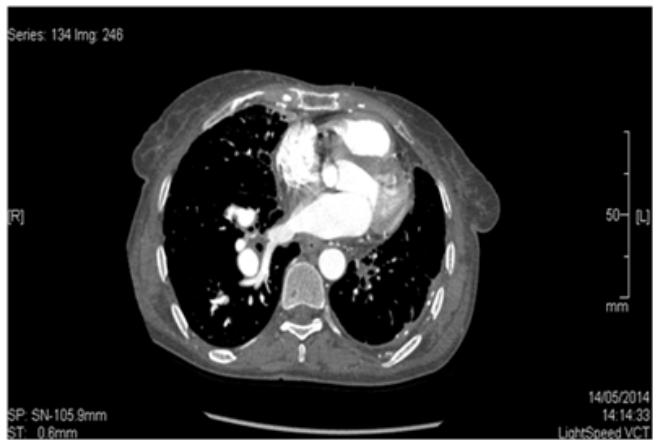

Figure I Right PV with small left hemithorax. The right PV is dilated. Other PVs are atretic.

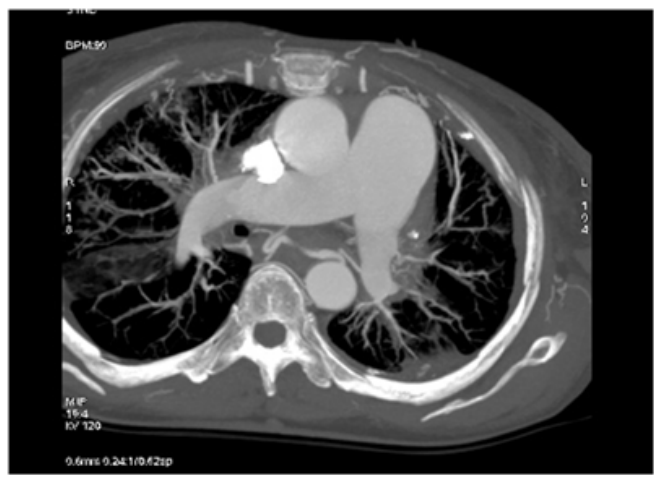

Figure 2 Dilated right pulmonary artery contrasting with small left pulmonary artery. 
Pulmonary hypertension, possible coexistent congenital heart disease and anatomy of anomalous venous return required cardiac catheterization including pulmonary angiography. Hemodynamic study showed a moderate pulmonary hypertension predominating on the left side. Blood gas analyses did not provide any signs of cardiac shunt (Table 1). Venous angiography confirms cardiac CT findings (Figure 3-5). The patient was discharged with inhaled corticosteroids and betamimetics. Evaluation at 6 months did not show any sign of aggravation in term of stress tolerance.

Table I Summary of hemodynamic and blood gas data

\begin{tabular}{|c|c|c|}
\hline & $\begin{array}{l}\text { Blood Oxygen } \\
\text { Saturation in } \\
\text { Percentage }\end{array}$ & $\begin{array}{l}\text { Blood Pressure in } \\
\text { mmHg (Mean) }\end{array}$ \\
\hline Innominate Veins & 82 & - \\
\hline Inferior Vena Cava & 78 & - \\
\hline Superior Vena Cava & 76 & - \\
\hline Left Pulmonary Artery & 76 & $\begin{array}{l}\text { 55/2I ( } 35) \\
\text { Mean capillary: } 33\end{array}$ \\
\hline Right Pulmonary Artery & 78 & $\begin{array}{l}\text { 54/2 I (35) } \\
\text { Mean capillary: I } 8\end{array}$ \\
\hline Right Atrium & 71 & -2 \\
\hline Right Ventricle & - & $53 / 2$ \\
\hline Left Ventricle & 88 & $100 / 7$ \\
\hline
\end{tabular}

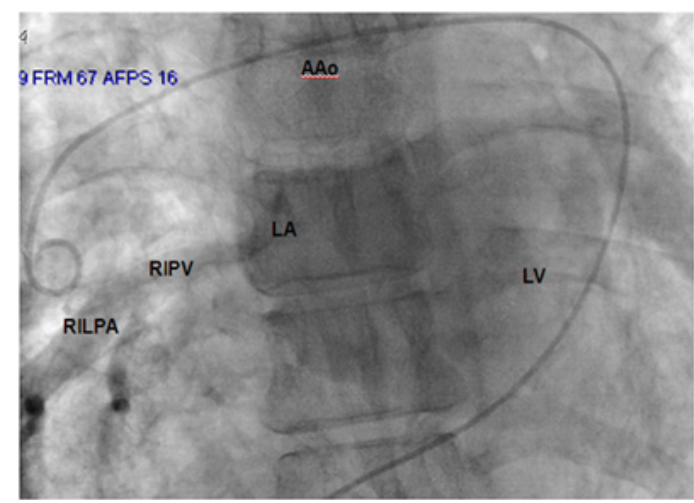

Figure 3 Dilated RIPV drained to LA.AAo:Ascending Aorta; LA: Left Atrium; LV: Left Ventricle; RIPV: Right Upper Pulmonary Vein; RILPA: Right Inferior Lobar Pulmonary Artery.

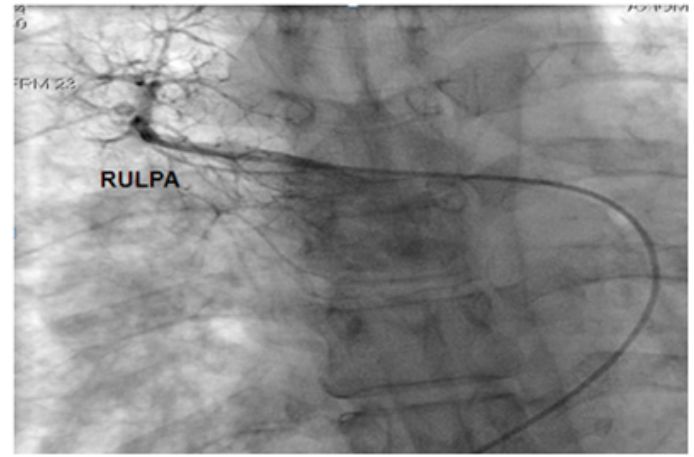

Figure 4 Hypotrophic RULPA without any veinous drainage. RULPA: Right Upper Lobar Pulmonary Artery.

\section{Discussion}

The etiologies of congenital PVA are unknown and it may be explained by a defect in the incorporation of the common PV into the left atrium. ${ }^{5}$ In some cases the atresia is limited to a short segment or to the connection with the left atrium. ${ }^{4}$ It may occur in either lung, with no right or left-sided predominance. ${ }^{1}$ Consequences in the affected lung includes hypertrophy, fibrosis and reduced lumen of the remaining veins ${ }^{6,7}$ in addition to interstitial lung fibrosis. Collateral extra-pulmonary vessels develop in an attempt to drain the affected lung, and their efficiency depends on the type of PVA. In fact, they are less effective in bilateral PVA, resulting in severe pulmonary venous obstruction. Contrast between ventilation and perfusion leading to inappropriate gas exchanges causes a reduction in the caliber of the pulmonary artery of the affected lung. The appearance of clinical symptoms or pulmonary arterial hypertension seem to depend on the balance between the supplying and draining vessels in the affected lung. ${ }^{6-8}$ Most cases of unilateral PVA occurs at the first years of life $e^{4}$ but presentation in adults has also been reported in both genders. ${ }^{2,4,6}$ Symptoms are variable, ranging from asymptomatic presentations $s^{9,10}$ to recurrent pulmonary infections, ${ }^{4,11}$ hemoptysis, ${ }^{11}$ and death. ${ }^{7,8}$ Pulmonary artery hypertension is also a frequent association. ${ }^{12}$ Cyanosis requires to eliminate a concomitant congenital heart defect, which occurs in $32 \%$ to $50 \%$ of cases. ${ }^{4,6,13}$ The severity of clinical manifestations depends on the number of atretic PVs, the presence of an associated congenital heart defect and the amount of collateral blood flow. ${ }^{3}$ Cases of unilateral PVA with contralateral pulmonary vein stenosis or atresia of the contralateral upper PV have been reported to have the worst clinical outcomes, ${ }^{14}$ in contrast with the clinical presentation of our patient. Indeed, in her case, symptoms appeared in adulthood and, during her pregnancies, a slight worsening of dyspnea was reported.

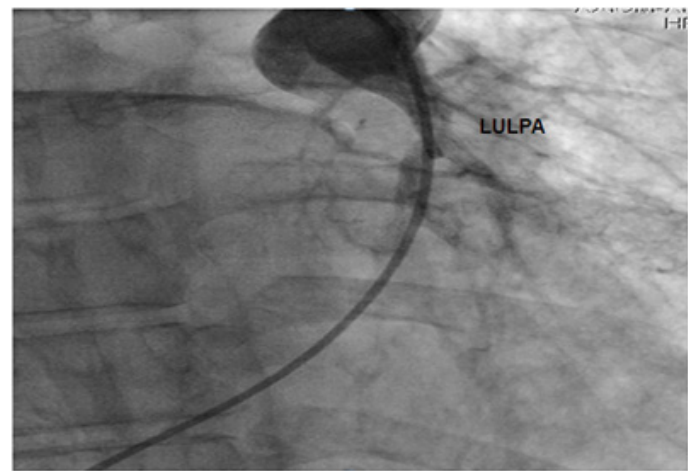

Figure 5 Hypotrophic LULPA with no veinous drainage. LULPA: Left Upper Lobar Pulmonary Artery.

Cardiac CT scan confirmed the absence of left PVs and the upper right $\mathrm{PV}$. The inferior right $\mathrm{PV}$ was dilated, probably to balance the upper one. The latter cardiac CT finding rectifies the TTE results. No connections to the left atrium in the expected site of insertion of the atretic PVs were observed, neither relics of PVs. Adult patients with such presentation may raise a diagnostic dilemma. One may argue that the absence of PVs may be an acquired anomaly secondary to a venous obstruction caused by thrombosis, mass lesion or fibrosis. Clinical history and laboratory tests do not provide other explanation of the lung fibrosis. The lack of bronchial or venous obstruction or any obstructive mediastinal mass in thoracic $\mathrm{CT}$ suggests a congenital origin. Thus magnetic resonance imaging was unnecessary to perform in the light of these results. Other abnormalities found in thoracic CT have been reported in other studies. ${ }^{15}$ Since our patient was still alive and did not undergo surgery, pathological correlation was not available, which is a limitation of this report. Follow-up of patients with few or no symptoms ${ }^{8,16}$ and selective embolization of systemic collaterals in cases of hemoptysis ${ }^{4}$ are therapeutic options. Pneumonectomy guided by ventilation perfusion scintigraphy ${ }^{13}$ may be suggested to inpatients with dyspnea, recurrent infections and to prevent pulmonary hypertension without significant left to right 
shunt. ${ }^{7,8}$ Some authors support surgery as a first therapeutic option, ${ }^{7}$ others chose to delay it in adult symptomatic patients provided they were followed-up for development of pulmonary hypertension ${ }^{8}$ which was our therapeutic choice.

\section{Acknowledgments}

None.

\section{Conflicts of interest}

Author declares there are no conflicts of interest.

\section{Funding}

None.

\section{References}

1. Vergales JE, West SC, Hoyer AW. Pulmonary vein atresia with severe contralateral pulmonary vein stenosis in a child. Pediatr Cardiol. 2012;33(4):663-665.

2. Mataciunas M, Gumbiene L, Cibiras S, et al. CT angiography of mildly symptomatic, isolated, unilateral right pulmonary vein atresia. Pediatr Radiol . 2009;39(10):1087-1090.

3. Goo HW, Park SH, Koo HJ, et al. Atresia of the bilateral pulmonary veins: a rare and dismal anomaly identified on cardiac CT. Pediatr Radiol. 2014;44(8):681-685.

4. Heyneman LE, Nolan RL, Harrison JK, et al. Congenital unilateral pulmonary vein atresia: radiologic findings in three adult patients. AJR Am J Roentgenol . 2001;177(3):681-685.

5. Cabrera A, Alcibar J. Bilateral pulmonary veins atresia. Rev EspCardiol. 2002;55(6):671-672.
6. Diego André E, Felipe Veras A, Felipe Soares T. Unilateral pulmonary veins atresia: evaluation by CT. Radiol Bras. 2013;46(6):376-378.

7. Pourmoghadam KK, Moore JW, Khan M, et al. Congenital unilateral pulmonary vein atresia: definitive diagnosis and treatment. Pediatr Cardiol . 2003;24(1):73-79.

8. Kim Y, Yoo IR, Ahn MI, et al. Asymptomatic adults with isolated, unilateral right pulmonary vein atresia: multidetector CT findings. $\mathrm{Br} \mathrm{J}$ Radiol . 2011;84(1002):e109-113.

9. Wang Y, Ma Y, Li B, et al. Unilateral left pulmonary vein atresia: radiologic findings in an adult case. Quant Imaging Med Surg. 2012;2(4):296.

10. Gasparetto TD, Daltro P, Marchiori E. Imaging findings of an asymptomatic child with pulmonary vein atresia. Pediatr Radiol. 2010;40(8):1458-1459.

11. Dixit R, Kumar J, Chowdhury V, et al. Case report: Isolated unilateral pulmonary vein atresia diagnosed on 128-slice multidetector CT. Indian J Radiol Imaging. 2011;21(4):253-256.

12. Swischuk LE, L'Heureux P. Unilateral pulmonary vein atresia. AJR. 1980;135(4):667-672.

13. Tissot C, Corbelli R, Aggoun Y, et al. Bronchoscopic diagnosis of asymptomatic unilateral pulmonary vein atresia in an infant. Pediatr Cardiol . 2008;29(5):976-979.

14. Shrivastava S, Moller JH, Edwards JE. Congenital unilateral pulmonary venous atresia with pulmonary veno-occlusive disease in contralateral lung: an unusual association. Pediatr Cardiol. 1986;7(4):213-219.

15. Beerman LB, Oh KS, Park SC, et al. Unilateral pulmonary vein atresia: clinical and radiographic spectrum. Pediatr Cardiol. 1983;4(2):105-112.

16. SavaÕBozbaÕ Ô, Varan B, Akçay Ô. Right pulmonary venous atresia: a case report and review of literature. Tuberk Toraks. 2012;60(3):254-257. 